\title{
Discussion of "Water Content Ratio: An Effective Substitute for Liquidity Index for Prediction of Shear Strength of Clays" by Beshy Kuriakose, Benny Mathews Abraham, A. Sridharan \& Babu T. Jose
}

\author{
P. J. Vardanega $(\mathbb{D} \cdot$ S. K. Haigh $(\mathbb{D}$
}

Received: 11 June 2017 / Accepted: 22 June 2017 / Published online: 29 June 2017

(C) The Author(s) 2017. This article is an open access publication

\section{List of symbols \\ a An intercept \\ $b \quad$ A slope \\ $c_{u} \quad$ Undrained shear strength \\ $c_{L} \quad$ Undrained shear strength at liquid limit \\ $e \quad$ Void ratio \\ $e_{L} \quad$ Void ratio at liquid limit \\ $I_{L} \quad$ Liquidity index \\ $n \quad$ Number of data points used to generate a best- fit line \\ $p \quad p$ value \\ $R^{2} \quad$ Coefficient of determination (where $R=$ the correlation coefficient) \\ $R D \quad$ Relative deviation $=100\left(1-R^{2}\right)^{0.5}($ see Waters and Vardanega 2009) \\ $R_{M W} \quad$ The computed ratio of strengths at the liquid limit and plastic limit \\ $S E \quad$ Standard error of a regression \\ $W C R \quad$ Water content ratio $=w / w_{L}$ \\ $w \quad$ Water content}

P. J. Vardanega $(\bowtie)$

Department of Civil Engineering, University of Bristol, Queen's Building, University Walk, Bristol BS8 1TR, UK e-mail: p.j.vardanega@bristol.ac.uk

\section{S. K. Haigh}

Department of Engineering, University of Cambridge, Trumpington Street, Cambridge CB2 1PZ, UK

e-mail: skh20@cam.ac.uk

$$
\begin{array}{ll}
w_{L} & \text { Liquid limit } \\
\alpha & w_{L} / w_{p}
\end{array}
$$

The discussers read the article by Kuriakose et al. (2017) with great interest, having completed another study on the variation of undrained strength with liquidity index (Vardanega and Haigh 2014). The authors draw attention to previous studies which use the $w / w_{L}\left(e / e_{L}\right)$ ratio to study the determination of the liquid limit (Nagaraj and Jayadeva 1981), and soil compressibility characteristics (e.g., Nagaraj and Murthy 1983, 1986; Griffiths and Joshi 1988). The discussers have some comments related to (a) the new relationships proposed by the authors and (b) whether the new method is sufficient to capture all the features of undrained strength variation, with changes in water content.

\section{Author's Proposed Relationship}

Equation (2) of the original paper appears to contain a small error. The discussers digitised the data from the author's paper (shown in Fig. 1 in the original paper) and fitted the following trend-line to the data:

$\log _{10}\left(c_{u}\right)=2.720-2.585\left(\frac{w}{w_{L}}\right)$

Eq. 1 has the following statistical measures: $R^{2}=0.935 ; \quad n=27 ; \quad S E=0.105 ; \quad R D=25.5 \%$; $p<0.001$.

Perhaps Eq. (2) in the original paper should have been: 
Fig. 1 Digitised Cochin clay data from Fig. 1 of Kuriakose et al. (2017) along with Eqs. 1 and 2 plotted (relevant statistical measures for Eq. 1 shown)

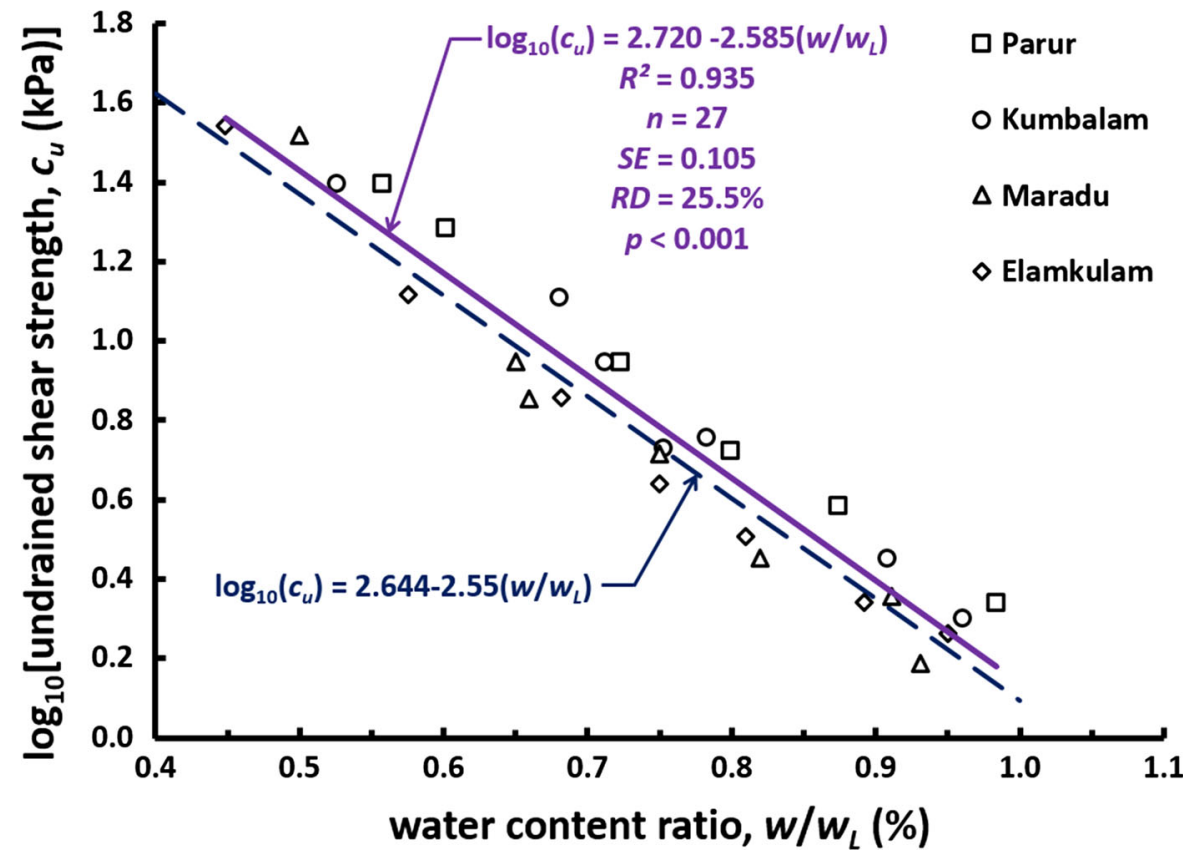

$\log _{10}\left(c_{u}\right)=2.644-2.55\left(\frac{w}{w_{L}}\right)$

and plastic limit is calculated to be about 30.6 which is more comparable with the factor of 34.3 reported by Vardanega and Haigh (2014) than the commonly assumed factor of 100 (e.g., Schofield and Wroth 1968 and Wood 1990).

$c_{u}=\left(c_{L}\right) 30.6^{\left(1-I_{L}\right)}$

In Eq. (3a) $c_{L}$ is computed to be about $1.36 \mathrm{kPa}$ (this reduction may be explained by the fact that in the article under discussion vane shear data is reported, and that as observed from the original paper's Fig. 3, Eq. (3a) underestimates the measured undrained strengths at liquid limit $\left(I_{L}=1\right)$. As the authors reiterate, Wroth and Wood (1978) reported a range of undrained strength at liquid limit from 0.7 to $2.65 \mathrm{kPa}$. Figure 2 shows Eqs. (3, 3a) and (4) plotted alongside the relationships of Leroueil et al. (1983) and Wroth and Wood (1978). The good agreement of the Cochin clay data-set with Eq. (4) is encouraging and further confirms that for semi-logarithmic trends linking undrained shear strength and liquidity index the often used factor of 100 between computed undrained strengths at plastic and liquid limits is too high. ${ }^{1}$

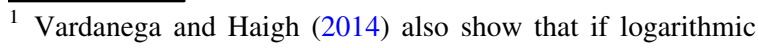
liquidity index is used the ratio between undrained strength at liquid limit and undrained strength at plastic limit appears to increase-as an artefact of the fitting function (see Vardanega and Haigh 2014 for more details).
} 
Fig. 2 Comparison of Leroueil et al. (1983) and Wroth and Wood (1978) and Eqs. 3, 3a and 4

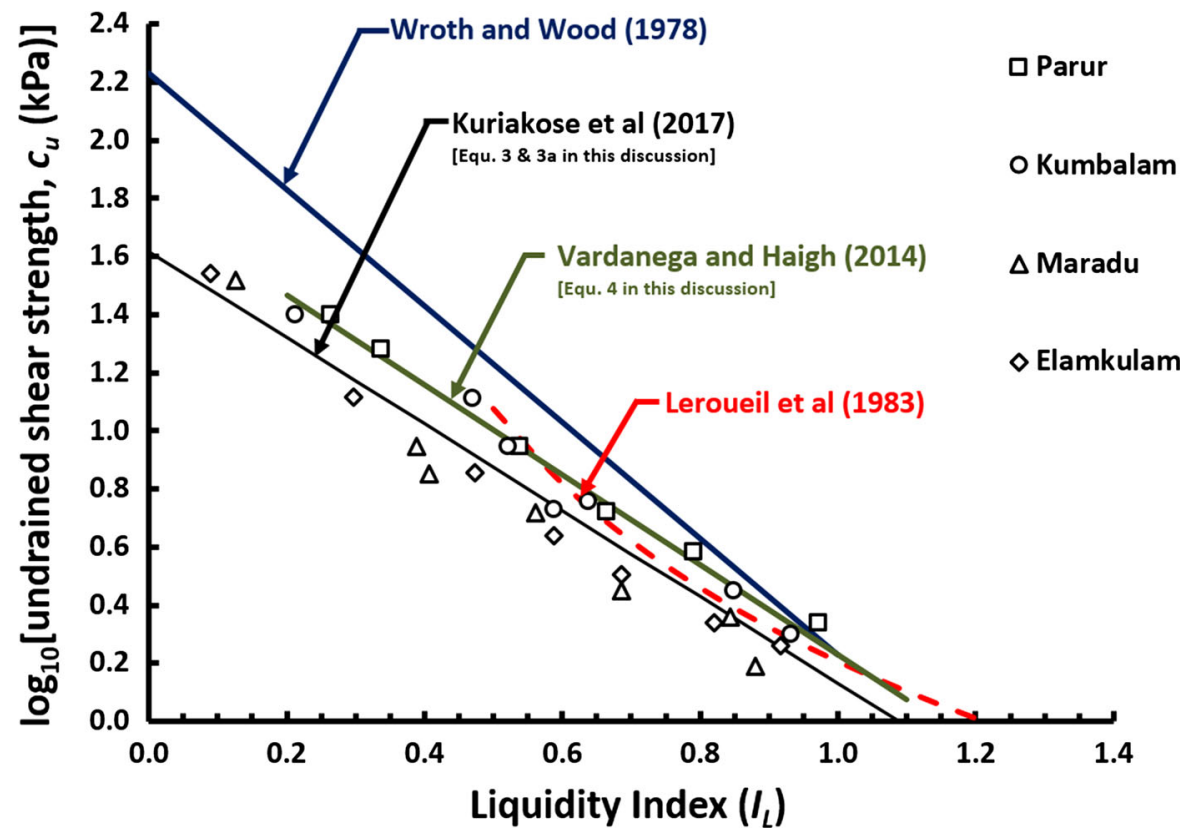

Fig. 3 Database from Vardanega and Haigh (2014) analysed using the water content ratio

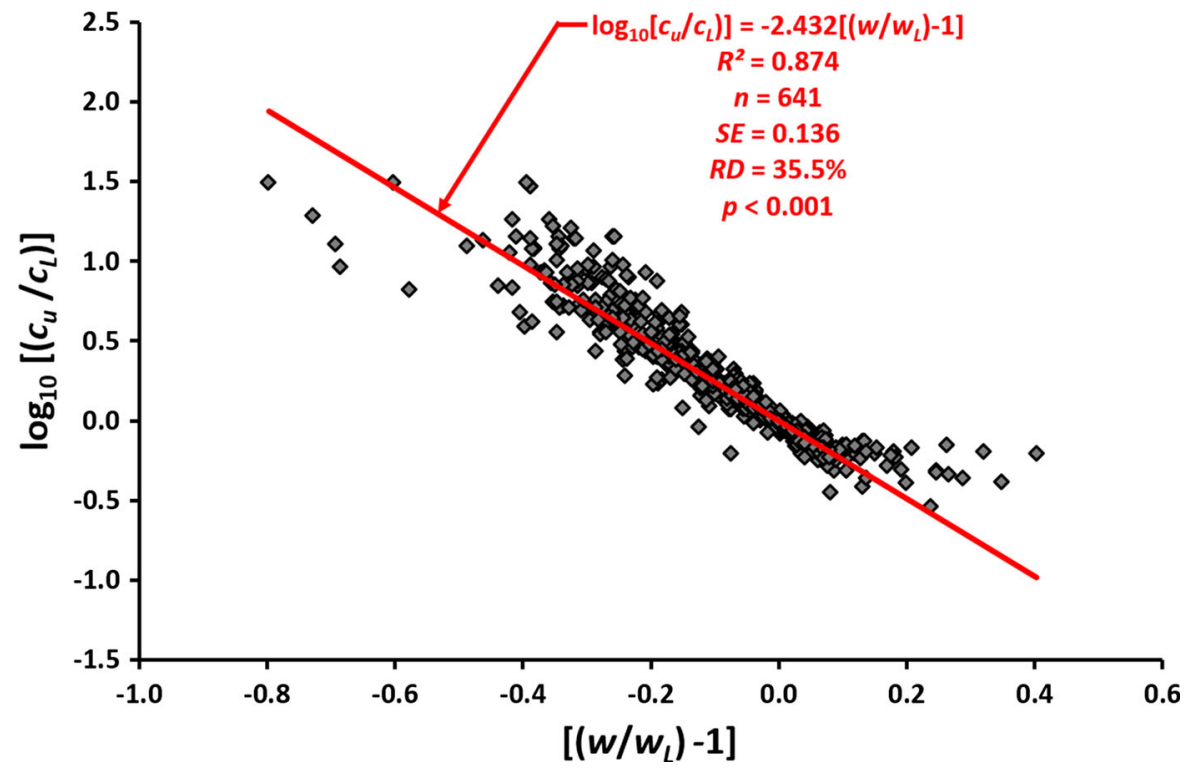

\section{Modelling Variation of Undrained Shear Strength with Water Content}

Now we turn to the suggestion of Kuriakose et al. (2017) of replacing liquidity index with water content ratio as a predictor of undrained soil strength. The discussers re-analysed the large database of fall-cone data that was reported in Vardanega and Haigh (2014) using the authors' method. For the sake of brevity the substantive details about the collection, sources of and analysis of the database will not be repeated here (readers should refer to Vardanega and Haigh 2014 for these details).

The best linear fit to the database (which can be rearranged into the form suggested by Kuriakose et al. 2017) relating values of undrained strength with WCR is given by Eq. (5). 
$\log _{10}\left[\frac{c_{u}}{c_{L}}\right]=-2.432\left[\left(\frac{w}{w_{L}}\right)-1\right]$

This can be re-arranged into the form of Eqs. (1) and (2) to give:

$\log _{10}\left(c_{u}\right)=2.662-2.432\left(\frac{w}{w_{L}}\right)$

Figure 3 shows the fitting of Eq. 5 to the database from Vardanega and Haigh (2014). Figure 4 shows that Eqs. (1) and (6) are functionally equivalent for the range of data shown. Figure 5 shows the accompanying predicted versus measured plot for Eq. (6). For the whole database (reported in Vardanega and Haigh 2014) an acceptable $R^{2}$ value of 0.874 is found for the method proposed by Kuriakose et al. (2017) (see Fig. 3). However, this is not as high as the $R^{2}$ value of 0.948 achieved from a fit using liquidity index in place of WCR (Vardanega and Haigh 2014).

In summary, the water content ratio is somewhat effective in characterising the changes in undrained strength with water content. Lab vane data from Kuriakose et al. (2017) was used to develop a relationship (given as Eq. 1 here-which is similar to Eq. 2) which compares well with that obtained from regression analysis of the fall-cone database of Vardanega and Haigh (2014) (Eq. 6) (see Fig. 4). However, the fit of Eq. (6) to the database is not as good as that given using Eq. (4) as more data-points are observed to migrate outside the $\pm 50 \%$ bounds on the prediction versus measured plot (cf. Fig. 5; Vardanega and Haigh 2014).

The increased uncertainty (shown on Fig. 5) originates from the variation of slopes seen for the relationships between WCR and undrained shear strength for different soils, which will now be demonstrated. Given that:

$I_{L}=\frac{w-w_{p}}{w_{L}-w_{p}}$

and defining, $\alpha=\frac{w_{L}}{w_{P}}$ and $W C R=\frac{w}{w_{L}}$ we can then write:

$I_{L}=\left(\frac{w-w_{p}}{w_{L}-w_{p}}\right)\left(\frac{\alpha W C R}{\alpha W C R}\right)=\frac{\alpha W C R-1}{\alpha-1}$

Therefore:

$I_{L}=\left(\frac{\alpha}{\alpha-1}\right) W C R-\left(\frac{1}{\alpha-1}\right)$

Equation 9 shows clearly how the fitting coefficients in Fig. 7 of the original paper (Kuriakose et al. 2017) can be determined and highlights the point the authors' made in the original paper that $W C R$ is related directly to $I_{L}$ via the $\alpha$ parameter. This said there must be a small error in the calculation of the ' $R$ ' values in Fig. 6 of the original paper as the best fit lines for a given soil on the two axes are functionally identical and should thus yield exactly the same value of the correlation coefficient $(R)$, not the small variation shown.
Fig. 4 Comparison of Eq. (1) and Eq. (6) (this discussion)

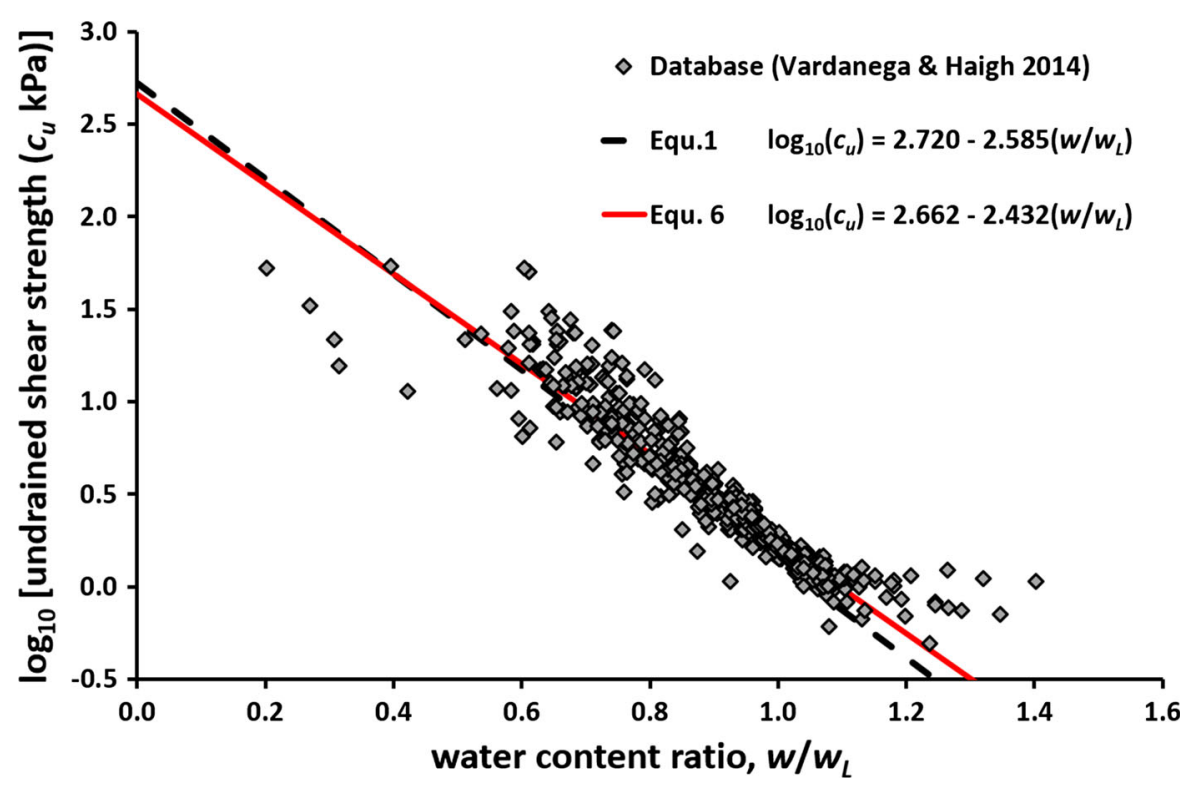


Fig. 5 Predicted versus measured plot (Eq. 6)

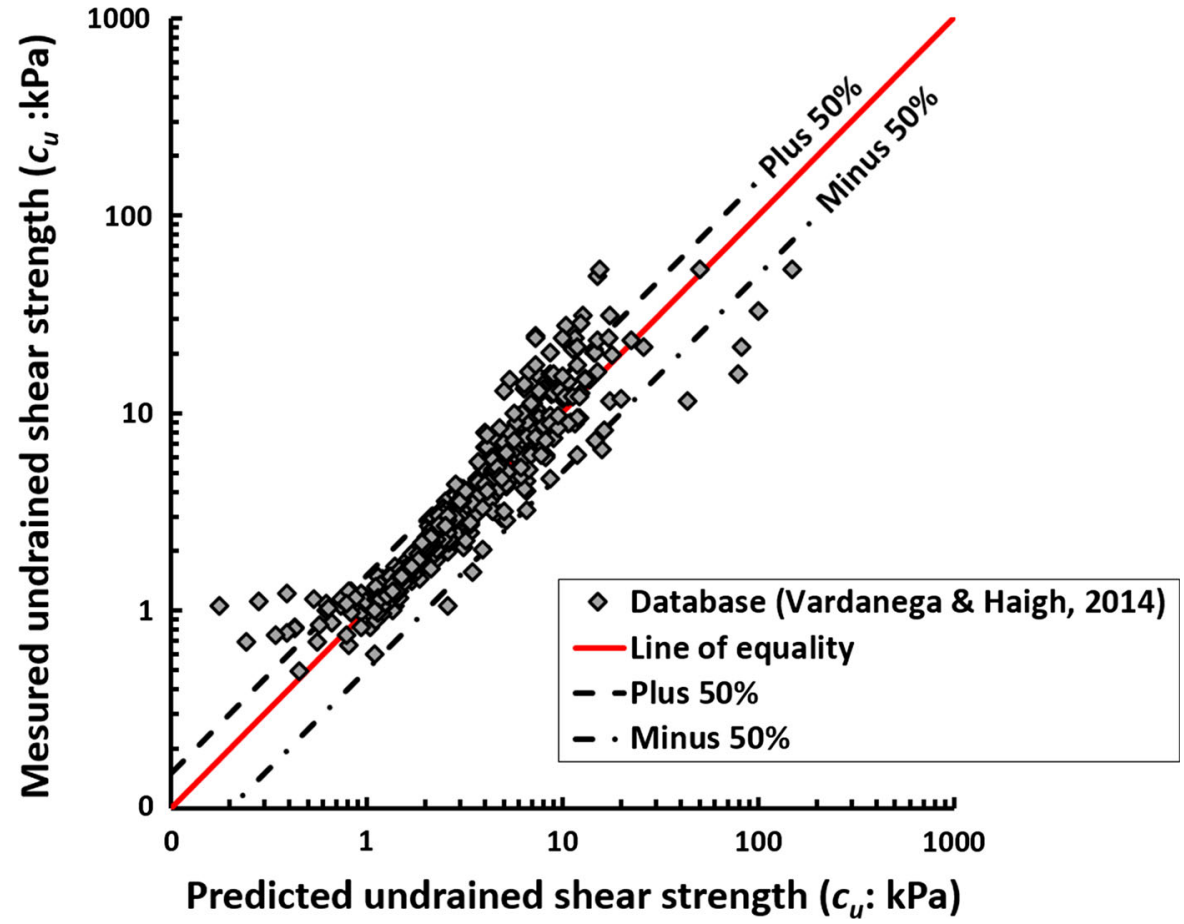

relationship between liquidity index and the logarithm of undrained strength. While $\ln \left(R_{M W}\right)$ varies between soils, the variability of $\left(\frac{\alpha}{\alpha-1}\right) \ln \left(R_{M W}\right)$ is greater. The coefficient of variation of $\ln \left(R_{M W}\right)$ for the soils in the Vardanega and Haigh (2014) database is computed to be about $16 \%$ whereas the coefficient of variation of $\left(\frac{\alpha}{\alpha-1}\right) \ln \left(R_{M W}\right)$ is about $24 \%$. This explains the improved $R^{2}$ computed when determining Eq. (4) $\left(R^{2}=0.948\right)$ compared with that for Eq. (6) (i.e. $\left.R^{2}=0.874\right)$.

In conclusion, while for a given soil the relationship between WCR and the logarithm of undrained shear strength is indeed linear, unless the relationship is being used solely for the extrapolation of measured undrained strength data for a given soil, there is no statistical basis to use a WCR relationship for undrained strength in preference to one based on liquidity index. One other point must also be made on extrapolation of undrained soil strength data using $W C R$. The linear relationships between the logarithm of undrained strength and water content break down close to the plastic limit. While this is a problem both for $W C R$ and $L I$ relationships, when using liquidity index it is obvious whether the water content of interest is approaching or drier than the plastic limit. The use of WCR obscures this trend, as the plastic 
limit is unknown and hence how close soil at a particular water content is to the onset of brittleness (see Haigh et al. 2013) is unclear. However, if extrapolations of fall cone or vane shear strength data close to the liquid limit are being performed then the approach suggested in Kuriakose et al. (2017) will probably suffice. When studying soil behaviour across the plastic range the discussers argue that liquidity index (or logarithmic liquidity index: see: Koumoto and Houlsby 2001) is still the preferred parameter.

Open Access This article is distributed under the terms of the Creative Commons Attribution 4.0 International License (http:// creativecommons.org/licenses/by/4.0/), which permits unrestricted use, distribution, and reproduction in any medium, provided you give appropriate credit to the original author(s) and the source, provide a link to the Creative Commons license, and indicate if changes were made.

\section{References}

Griffiths FJ, Joshi RC (1988) Identification of cementation in overconsolidated clays. Géotechnique 38(3):451-452. doi:10.1680/geot.1988.38.3.451

Haigh SK, Vardanega PJ, Bolton MD (2013) The plastic limit of clays. Géotechnique 63(6):435-440. doi:10.1680/geot.11. P.123
Koumoto T, Houlsby GT (2001) Theory and practice of the fall cone test. Géotechnique 51(8):701-712. doi:10.1680/geot. 2001.51.8.701

Kuriakose B, Abraham BM, Sridharan A, Jose BT (2017) Water content ratio: an effective substitute for liquidity index for prediction of shear strength of clays. Geotech Geol Eng. doi:10.1007/s10706-017-0193-0

Leroueil S, Tavenas F, Bihan JL (1983) Propriétés caractéristiques des argiles de l'est du Canada. Can Geotech J 20(4):681-705. doi:10.1139/t83-076 (in French)

Nagaraj TS, Jayadeva MS (1981) Re-examination of one point methods of liquid limit determination. Géotechnique 31(3):413-425. doi:10.1680/geot.1981.31.3.413

Nagaraj TS, Murthy BRS (1983) Rationalisation of Skempton's compressibility equation. Géotechnique 33(4):433-444. doi:10.1680/geot.1983.33.4.433

Nagaraj TS, Srinivasa Murthy BR (1986) A critical reappraisal of the compression index equation. Géotechnique 36(1):27-32. doi:10.1680/geot.1986.36.1.27

Schofield AN, Wroth CP (1968) Critical state soil mechanics. McGraw-Hill, United Kingdom

Vardanega PJ, Haigh SK (2014) The undrained strength-liquidity index relationship. Can Geotech J 51(9):1073-1086. doi:10.1139/cgj-2013-0169

Waters TJ, Vardanega PJ (2009) Re-examination of the coefficient of determination (r2) using road materials engineering case studies. Road Transp Res 18(3):3-12

Wood DM (1990) Soil behaviour and critical state soil mechanics. Cambridge University Press, United Kingdom

Wroth CP, Wood DM (1978) The correlation of index properties with some basic engineering properties of soils. Can Geotech J 15(2):137-145. doi:10.1139/t78-014 